\title{
A meta-analysis of obesity and the risk of pancreatic cancer
}

\author{
A Berrington de Gonzalez ${ }^{*, 1}$, S Sweetland' and E Spencer' \\ 'Cancer Research UK Epidemiology Unit, University of Oxford, Gibson Building, Radcliffe Infirmary, Oxford OX2 6HE, UK
}

\begin{abstract}
Smoking and diabetes are the only established risk factors for pancreatic cancer. Findings from recent studies suggest that obesity may also be associated with an increased risk of pancreatic cancer, but several earlier studies were less conclusive. We examined this relationship in a meta-analysis of published data. Six case-control and eight cohort studies involving 639 I cases of pancreatic cancer were identified from a computer-based literature search from 1966 to 2003. The relative risk per unit increase in body mass index was estimated for each of the studies from the published data. In a random effects model, the summary relative risk per unit increase in body mass index was 1.02 ( $95 \% \mathrm{Cl}: 1.01-1.03)$. There was some evidence of heterogeneity between the studies' results $(P=0.1)$. The summary relative risk estimates were slightly higher for studies that had adjusted for smoking and for case-control studies that had not used proxy respondents. The estimated per unit increase in body mass index would translate into a relative risk of 1.19 (95\% Cl: $1.10-1.29)$ for obese people $\left(30 \mathrm{~kg} \mathrm{~m}^{-2}\right)$ compared to people with a normal body weight $\left(22 \mathrm{~kg} \mathrm{~m}^{-2}\right)$. These results provide evidence that the risk of pancreatic cancer may be weakly associated with obesity. However, the small magnitude of the summary risk means the possibility of confounding cannot be excluded.

British Journal of Cancer (2003) 89, 5I9-523. doi: I0.1038/sj.bjc.660II 40 www.bjcancer.com
\end{abstract}

(c) 2003 Cancer Research UK

Keywords: pancreatic neoplasms; risk factors; obesity; body mass index; anthropometry

Pancreatic cancer is the fifth most common cause of cancer mortality in the European Union and North America and is responsible for approximately 70000 deaths in these regions annually (Ferlay et al, 2001). Smoking and diabetes are the only well-established risk factors for this invariably fatal disease (Gapstur and Gann, 2001). Smoking, however, is thought to account for at most $20-40 \%$ of pancreatic cancer cases (International Agency for Research on Cancer, 1990). The findings from several large US cohort studies suggest that obesity (defined as body mass index of at least $30 \mathrm{~kg} \mathrm{~m}^{-2}$ ) may also be a risk factor for pancreatic cancer (Michaud et al, 2001; Calle et al, 2003). The results of several earlier observational studies were less conclusive. The aim of this meta-analysis was to examine the relationship between pancreatic cancer and body mass index in relevant published epidemiological studies.

\section{MATERIALS AND METHODS}

\section{Data sources}

Epidemiological studies were identified through searches of the electronic databases MEDLINE (1966-2003), EMBASE (19802003) and the Science Citation Index (1981-2003) and also from citations in the selected papers and review articles. The key words that were used for the search were pancreatic cancer, obesity, body mass index, anthropometric factors and risk factors. The search was limited to human studies and restricted to peer-reviewed articles. No language or date limitations were imposed.

*Correspondence: Dr A Berrington de Gonzalez;

E-mail: amy.berrington@cancer.org.uk

Received 21 March 2003; revised 29 May 2003; accepted 29 May 2003

\section{Study selection}

Each study was required to have published information on the number of study participants and on age-adjusted or age-matched relative risks (or odds ratios, subsequently referred to as relative risks), and their corresponding confidence intervals according to categories of body mass index or per unit increase in body mass index, or data that would allow this to be estimated. Details of the boundaries that were used for the categories of body mass index were also required.

In total, 16 studies were identified in the search of which 14 satisfied the criteria for inclusion. A US case-control study (Lyon et al, 1993) was not included because the authors only published a crude relative risk for the top tertile to the lowest tertile of body mass index, and did not provide any information on the boundaries for the tertiles. A Chinese case-control study (Ji et al, 1996) was excluded because there is evidence that adiposityassociated health effects occur at lower levels of body mass index among Asian populations than among Western populations (WHO, IASO and IOT, 2000). The studies that were included were all of either European or North American populations.

\section{Data extraction}

For each eligible study, the following information was extracted independently by two reviewers: country and year of diagnosis of the cases; study design (cohort or case-control and type of controls); measured or self-reported weight; at what time point body weight was assessed; whether proxy respondents had been used; categories of body mass index; relative risk and $95 \%$ confidence intervals for each category of body mass index; estimated relative risk per unit increase in body mass index; adjustment factors used in the analysis. The most fully adjusted relative risks were extracted from each published article. 


\section{Statistical methods}

Body mass index was defined as weight height ${ }^{-2}$ in all the studies except one. Silverman et al calculated body mass index as weight height ${ }^{-1.5}$ for women only. To translate these categories of body mass index into weight height ${ }^{-2}$, we divided the body mass index categories by the square root of height where height was set to $1.64 \mathrm{~m}$, the mean height of women in a large US cohort study (Michaud et al, 2001).

Only three studies (Friedman and van den Eeden, 1993; Michaud et al, 2001) had reported results in the form of a relative risk per unit increase in body mass index. Therefore, for the other studies it was necessary to estimate the relative risk per unit increase in body mass index by regressing the risks reported according to categories of body mass index on the mid-point of each category. This was done using weighted least squares regression analysis with the weights taken as the variance of the log relative risk. Adjustment was made for the lack of independence of risks within each study (because the risks are all estimated with the same baseline) using a method for combining nonindependent strata (Berrington and Cox, 2003). For any open-ended categories of body mass index (e.g. $<25 \mathrm{~kg} \mathrm{~m}^{-2}$ ), the mid-points were estimated assuming that body mass index was normally distributed and by taking the midpoint between the specified boundary and the estimated first percentile for estimation of a lower limit or 99th percentile for an upper limit. A sensitivity analysis was conducted to investigate the effect of the choice of boundaries on the slope estimates. Two case-control studies (Howe et al, 1990; Zatonski et al, 1991) only published mean values for body mass index for cases and controls. Approximate slope estimates were calculated for these studies using the method described by Greenland (1987).

Relative risks for each study are plotted as black squares whose size is inversely proportional to the variance of the logarithm of the relative risk. Diamonds represent summary relative risks for the pooled data, calculated using the method of empirically weighted least squares where the weights are defined as the inverse of the variance of the log relative risks under a random effects model (Cox, 1977). All but five of the studies had reported results for male and female patients separately. The results for Howe et al were also reported for proxy and nonproxy respondents separately. To examine other potential sources of variability, summary results were stratified according to sex and other study design and adjustment factors. Heterogeneity between these factors was estimated using a meta-regression model (Ursin et al, 1995).

\section{RESULTS}

Overall six case-control (Bueno de Mesquita et al, 1990; Howe et al, 1990; Ghadirian et al, 1991; Zatonski et al, 1991; Silverman et al, 1998; Hanley et al, 2001) and eight cohort studies (Friedman and van den Eeden, 1993; Shibata et al, 1994; Gapstur et al, 2000; Michaud et al, 2001; Stolzenberg-Solomon et al, 2002; Calle et al, 2003; Lee et al, 2003) were eligible for inclusion in this metaanalysis. In total, these studies included 6391 cases of pancreatic cancer (Table 1). Most of the studies (11) were of North American populations. Height and weight were measured in three of the cohort studies and were self-reported in all the other studies. All of the case-control studies used population-based controls. Four of the case-control studies used proxy respondents because some of the cases were too ill to be interviewed.

The estimated increase in relative risk per unit increase in body mass index for each of the 14 studies is shown in Figure 1 separately for male and female subjects (wherever this information was available). There was some evidence of heterogeneity between the estimates $(P=0.1)$, with 15 of the 22 estimates suggesting a positive association between body mass index and the risk of pancreatic cancer and the remainder a negative one. Overall, there was evidence of a small positive increase in risk per unit increase in body mass index and the summary relative risk was $1.02(95 \%$ CI: $1.01-1.03)$. This per unit increase would be equivalent to a relative risk of $1.19(95 \%$ CI: $1.10-1.29)$ for obese people $\left(30 \mathrm{~kg} \mathrm{~m}^{-2}\right)$ compared to people with a normal body weight $\left(22 \mathrm{~kg} \mathrm{~m}^{-2}\right)$. The results that had the greatest influence on the summary risk were the female subjects from the study by Howe (using proxy respondents), and the studies by StolzenbergSolomon and Calle. In particular, if the female patients from the Howe (proxy respondents) study were excluded, then the summary relative risk increased to 1.03 .

Table I Details of the I4 studies included in the meta-analysis

\begin{tabular}{|c|c|c|c|c|c|c|c|c|c|}
\hline \multirow[b]{2}{*}{ Study first author Year (Country) } & \multirow{2}{*}{$\begin{array}{l}\text { Study } \\
\text { design }\end{array}$} & \multirow{2}{*}{$\begin{array}{l}\text { Period of } \\
\text { diagnosis }\end{array}$} & \multirow{2}{*}{$\begin{array}{l}\text { Time of weight } \\
\text { estimate }\end{array}$} & \multirow[b]{2}{*}{ Sex } & \multicolumn{2}{|c|}{ Number of } & \multirow[b]{2}{*}{ Proxies } & \multicolumn{2}{|c|}{ Adjustments } \\
\hline & & & & & Cases & Controls & & Smoking & Diabetes \\
\hline \multirow[t]{2}{*}{ Bueno de Mesquita 1990 (Netherlands) } & $\mathrm{C}-\mathrm{C}$ & $1984-1988$ & 2 years before interview & M & 90 & 232 & Yes & Yes & No \\
\hline & & & & $\mathrm{F}$ & 74 & 248 & & & \\
\hline \multirow[t]{2}{*}{ Howe 1990 (Canada) } & $\mathrm{C}-\mathrm{C}$ & $1983-1986$ & 2 years before interview & M & $|4|$ & 270 & Yes & No & No \\
\hline & & & & $\mathrm{F}$ & 108 & 235 & & & \\
\hline Ghadirian 199| (Canada) & $\mathrm{C}-\mathrm{C}$ & $1984-1988$ & 2 years before interview & $M, F$ & 179 & 239 & Yes & Yes & No \\
\hline Zatonski I99| (Poland) & $\mathrm{C}-\mathrm{C}$ & $1985-1988$ & Not known & $M, F$ & 110 & 195 & Yes & No & No \\
\hline Friedman 1993 (USA) & Cohort & $1945-1988$ & Prospective (measured) & $M, F$ & 450 & 2687 & NA & Yes & No \\
\hline Shibata 1994 (USA) & Cohort & $1981-1990$ & Prospective & $M, F$ & 65 & NA & NA & Yes & No \\
\hline \multirow[t]{2}{*}{ Silverman 1998 (USA) } & $C-C$ & $1986-1989$ & Usual in adulthood & M & 218 & $|23|$ & No & Yes & Yes \\
\hline & & & & $\mathrm{F}$ & 213 & 747 & & & \\
\hline \multirow[t]{2}{*}{ Gapstur 2000 (USA) } & Cohort & $1967-1995$ & Prospective (measured) & M & 96 & NA & NA & Yes & Yes \\
\hline & & & & $\mathrm{F}$ & 43 & NA & & & \\
\hline \multirow[t]{2}{*}{ Michaud 200I (USA) } & Cohort & $1976-1998$ & Prospective & M & 140 & NA & NA & Yes & Yes \\
\hline & & & & $\mathrm{F}$ & 210 & NA & & & \\
\hline \multirow[t]{2}{*}{ Hanley 200I (Canada) } & $\mathrm{C}-\mathrm{C}$ & $1994-1997$ & 2 years before interview & M & 173 & 1074 & No & Yes & No \\
\hline & & & & $\mathrm{F}$ & 139 & $|19|$ & & & \\
\hline Stolzenberg-Solomon 2002 (Finland) & Cohort & $1985-1997$ & Prospective (measured) & M & 172 & NA & NA & NA & Yes \\
\hline Lee 2003 (USA) & Cohort & $1962-1995$ & Prospective & $M, F$ & 212 & NA & NA & NA & Yes \\
\hline \multirow[t]{2}{*}{ Calle 2003 (USA) } & Cohort & $1982-1998$ & Prospective & M & 1908 & NA & NA & Yes & No \\
\hline & & & & $\mathrm{F}$ & 1650 & NA & & & \\
\hline
\end{tabular}

$\mathrm{NA}=$ not applicable; $C-C=$ case - control study; $M=$ males; $F=$ females.

Michaud (200I) published the results of two cohort studies in one paper. The male subjects were one cohort study (Health Professionals' Follow-up study) and the female subjects were the other (Nurses' Health Study) 


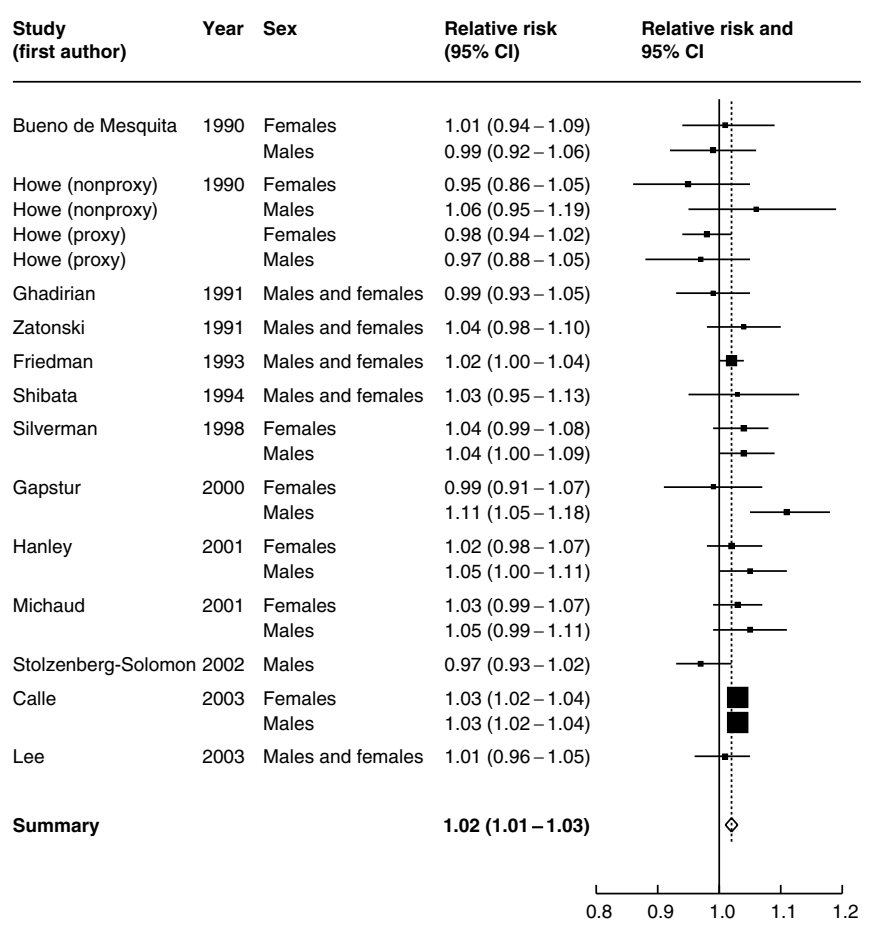

Figure I Estimated relative risk and $95 \%$ confidence interval $(95 \% \mathrm{Cl})$ of pancreatic cancer for a unit increase in body mass index.

For most of the studies, the risk per unit increase in body mass index had to be estimated from published data. To assess the sensitivity of the summary relative risk to the estimation of the mid-points for the open-ended categories of body mass index (e.g. $<25 \mathrm{~kg} \mathrm{~m}^{-2}$ ), the categories were reassigned mid-points that were 5,10 and $15 \%$ below (for the bottom category or above for the top category) the specified boundary. For example, if the baseline category was $<23 \mathrm{~kg} \mathrm{~m}^{-2}$, then the category mid-point was set at $21.85,20.70$ and $19.55 \mathrm{~kg} \mathrm{~m}^{-2}$ and the relative risk per unit increase in body mass index was recalculated. The overall summary relative risk was quite insensitive to these changes. The use of $5 \%$ above and below the bottom and top category increased the summary relative risk to 1.03 (95\% CI: $1.01-1.04$ ), whereas 15 and $10 \%$ left it unchanged).

To explore the sources of heterogeneity between the studies, the relative risk estimates were calculated for subgroups of studies defined according to various covariates (see Figure 2). The summary relative risk for a unit increase in body mass index was marginally higher for male than for female subjects (1.03 compared to 1.02) and also for cohort compared to case-control studies (1.03 compared to 1.02). The results from the North American studies were also higher than the European studies (1.02 and 1.00 , respectively). Studies in which height and weight had been measured had a slightly lower summary relative risk (1.02) than studies in which they had been self-reported (1.03). When we restricted the studies to those that had adjusted for smoking, the summary relative risk increased to 1.03 . Finally, although diabetes is now an established risk factor for pancreatic cancer some of the studies had not adjusted for diabetes. In the six studies that had made this adjustment, the summary per unit increase in relative risk was 1.03 compared to 1.02 in the studies that had not adjusted for diabetes. Tests for heterogeneity between each of these summary results generally lacked power; however, there was some evidence of significant differences in the summary relative risk according to whether an adjustment for smoking had been made $(P=0.04)$. Some of the case-control studies had used proxy respondents if cases were too ill to be interviewed and there was

\begin{tabular}{lcccc} 
Group of studies & $\begin{array}{l}\text { No. of } \\
\text { studies }\end{array}$ & Relative risk (95\% Cl) & Relative risk and 95\% Cl \\
\hline All & $\mathbf{1 4}$ & $\mathbf{1 . 0 2 ( 1 . 0 1 - 1 . 0 3 )}$ & \\
Males & 8 & $1.03(1.01-1.06)$ & \\
Females & 7 & $1.02(1.00-1.03)$ & \\
Case-control & 6 & $1.02(1.00-1.03)$ & \\
Cohort & 8 & $1.03(1.01-1.04)$ & \\
North American studies & 11 & $1.02(1.01-1.03)$ & \\
European studies & 3 & $1.00(0.97-1.03)$ & \\
Measured anthropometry & 3 & $1.02(0.97-1.07)$ & \\
Self-reported anthropometry & 11 & $1.03(1.02-1.03)$ & \\
Smoking adjustment & 11 & $1.03(1.02-1.03)$ & \\
No smoking adjustment & 2 & $1.00(0.96-1.03)$ & \\
Diabetes adjustment & 6 & $1.03(1.00-1.06)$ & \\
No diabetes adjustment & 8 & $1.02(1.02-1.03)$ & \\
Proxies used & 4 & $0.99(0.97-1.02)$ & \\
No proxies used & 3 & $1.03(1.01-1.06)$ & \\
& & &
\end{tabular}

Figure 2 Estimated relative risk and $95 \%$ confidence interval $(95 \% \mathrm{Cl})$ of pancreatic cancer for a unit increase in body mass index in different groups of studies.

evidence also of some heterogeneity between these risk estimates $(P=0.02)$. In the studies that had used proxy respondents, the summary relative risk was lower $(0.99)$ than in those that did not use proxy respondents (1.03).

\section{DISCUSSION}

Overall, there was evidence of a small positive increase in the risk of pancreatic cancer per unit increase in body mass index. A unit increase in body mass index for a male patient of $1.78 \mathrm{~m} \mathrm{(5 \textrm {ft } 1 0 \mathrm { in } )}$ represents weight gain of about $3 \mathrm{~kg}(6.6 \mathrm{lbs})$. For a female patient of $1.64 \mathrm{~m}$ ( 5 feet 5 inches), a unit increase in body mass index represents weight gain of about $2.5 \mathrm{~kg}$ ( $5.5 \mathrm{lbs})$. The observed per unit increase in relative risk translates into a $19 \%$ higher risk of pancreatic cancer for obese people (body mass index $>30 \mathrm{~kg} \mathrm{~m}^{-2}$ ) compared to those of normal body weight $\left(22 \mathrm{~kg} \mathrm{~m}^{-2}\right)$. There was, however, some evidence of heterogeneity between the studies' results $(P=0.1)$. The summary relative risk estimates were slightly higher for studies that had adjusted for smoking and for casecontrol studies that had not used proxy respondents.

As this meta-analysis was based on published data, there is the possibility that publication bias could have affected the results. The relative risks are presented in chronological order of publication, and there was no visual evidence of publication bias (Figure 1). Neither was there evidence that the smaller studies tended to have positive results more frequently. However, it is not possible to rule out the possibility that further data, which show no evidence of an association between body mass index and pancreatic cancer risk, exist but have not been published.

Two case-control studies that had published information on body mass index and the risk of pancreatic cancer could not be included in this analysis. A US case-control study of 149 cases of pancreatic cancer conducted in Utah (Lyon et al, 1993), which was not included because the authors only published crude relative risks for the highest to lowest tertile and provided no information on the tertile boundaries, found a relative risk for the highest tertile of body mass index compared to the lowest of 0.83 (95\% CI: $0.43-1.58)$ for men and 1.05 (95\% CI: $0.53-2.08)$ for women. Although the study findings were null, the CI were wide and were therefore not inconsistent with our summary relative risk of 1.19 for obese people (body mass index $>30 \mathrm{~kg} \mathrm{~m}^{-2}$ ) compared to those of normal body weight $\left(22 \mathrm{~kg} \mathrm{~m}^{-2}\right)$. A Chinese case-control study (Ji et al, 1996) was not included because there is evidence 
that adiposity-associated health effects occur at lower levels of body mass index among Asian populations than among Western population (WHO, IASO and IOT, 2000). It was not clear therefore that a relative risk per unit increase in body mass index would have the same meaning in an Asian as in a Western population. In this study, which included 483 cases of pancreatic cancer, there was evidence of an increasing risk of pancreatic cancer with increasing body mass index in men $(P=0.05)$ but not in women $(P=0.31)$. The relative risk for the top quartile of body mass index in male patients ( $>22.4$ compared to $<19.5 \mathrm{~kg} \mathrm{~m}^{-2}$ ) was 1.38 (95\% CI: $0.91-2.08)$ and for female patients, it was $1.46(95 \% \mathrm{CI}$ : $0.85-2.51)\left(>23.1 \mathrm{~kg} \mathrm{~m}^{-2}\right.$ compared to $\left.<19.5 \mathrm{~kg} \mathrm{~m}^{-2}\right)$.

The studies that were included in this meta-analysis contained $91 \%$ of the cancer cases that were available and the results from the two studies that could not be included were not inconsistent with the findings from this meta-analysis. Two other record linkage cohort studies of obese individuals both found an elevated risk of pancreatic cancer compared to expected rates in the general population of 1.7 and 1.5 (95\% CI: 1.1-1.9), respectively (Moller et al, 1994; Wolk et al, 2001). The study by Wolk et al found that the risk decreased with age from 2.5 (95\% CI: 1.5-4.0) for those aged $<60$ years, to $2.0(1.3-2.8)$ for $60-69$ year olds and $0.7(0.4-$ 1.2) for those aged $70+$ years.

Smoking and diabetes are both potential confounding factors for the relationship between obesity and pancreatic cancer. If there is an association between body mass index and smoking, however, it is more likely to be a negative one, as current smokers have been observed to weigh less than nonsmokers (Istvan et al, 1992). Therefore, ignoring confounding by smoking could make the association between obesity and pancreatic cancer less positive. Only two of the studies that were included in this meta-analysis had not adjusted the risk estimates for smoking (Howe et al, 1990; Zatonski et al, 1991). When these studies and the cohort study of smokers (Stolzenberg-Solomon et al, 2002) were excluded, the summary relative risk per unit increase in body mass index was slightly higher (1.03). In the cohort study by Calle et al, the risk associated with obesity was investigated in men and women who had never smoked. In this subgroup, the relative risk of pancreatic cancer mortality for a body mass index of $35-39.9 \mathrm{~kg} \mathrm{~m}^{-2}$ was 2.61 compared to those with a normal body mass index (18.5$24.9 \mathrm{~km} \mathrm{~m}^{-2}$ ). In the analysis with adjustment for smoking, the relative risks were somewhat lower at 1.49 for men and 1.41 for women.

Long-standing diabetes has also been established as a risk factor for pancreatic cancer with duration of diabetes of 5 years or more being associated with a two-fold increased risk of pancreatic cancer (Everhart and Wright, 1995). Hence, a history of diabetes could positively confound the relationship between the risk of pancreatic cancer and body mass index. However, in the six studies in this meta-analysis that had adjusted for a history of diabetes, the risks associated with a unit increase in body mass index were actually marginally higher than in the studies that had not adjusted for this risk factor (1.03 compared to 1.02). In their case-control study, Silverman et al also published the risks associated with obesity cross-classified by a history of diabetes. Although there was evidence of an increase in risk for both those with and without the disease, within each level of body mass index diabetics had a higher risk of pancreatic cancer than nondiabetics (Silverman et al, 1999). Future studies need to examine the relationship between obesity and pancreatic cancer in more detail in those who have never smoked and in those without a history of diabetes.

All of the studies except for Gapstur et al, Friedman et al and Stolzenberg-Solomon et al relied upon self-reported height and weight and it is possible that weight may have been underreported, especially by overweight or obese individuals (Spencer et al, 2002). Such under-reporting could result in overestimation of the dose-response relationship. The summary relative risk estimate for the studies that had measured anthropometry was marginally lower than those that relied upon self-reporting (1.02 vs 1.03). In case-control studies, under-reporting of weight could be a potential bias if it occurred unequally among cases and controls. Case-control studies could also be biased if the individuals in the control group were more 'health conscious' and thus less likely to be overweight than the cases. However, the summary relative risks in the case-control studies (1.02) were actually slightly lower than those for the cohort studies (1.03).

Obesity may be related to an increased risk of several other cancers including those of the endometrium, colorectum, oesophagus, kidney and postmenopausal breast cancer (IARC, 2002). Some of the mechanisms that have been suggested to explain these relationships may also be relevant for pancreatic cancer, including the hypothesis that insulin resistance and abnormal glucose metabolism may be a factor in pancreatic cancer development (Gapstur et al, 2000). The association between diabetes and pancreatic cancer risk (Everhart and Wright, 1995) supports this hypothesis, and further support for this is given by findings that physical activity may be associated with a decreased risk of pancreatic cancer (Hanley et al, 2001; Michaud et al, 2001).

This meta-analysis of the available observational data provides evidence that the risk of pancreatic cancer may increase slightly with increasing body mass index, and that obese individuals may have a risk that is $19 \%$ higher than those with a normal body mass index. However, the small magnitude of the summary relative risk means that the possibility of confounding cannot be excluded.

\section{REFERENCES}

Berrington A, Cox DR (2003) Generalized least squares for the synthesis of correlated information. Biostat 4: 423-431

Bueno de Mesquita HB, Moerman CJ, Runia S, Maisonneuve P (1990) Are energy and energy-providing nutrients related to exocrine carcinoma of the pancreas? Int J Cancer 46: $435-444$

Calle EE, Rodriguez C, Walker-Thurmond K, Thun MJ (2003) Overweight, obesity, and mortality from cancer in a prospectively studied cohort of US adults. $N$ Engl J Med 348: $1625-1638$

Cox DR (1977) Analysis of Binary Data. London: Chapman and Hall Ltd

Everhart J, Wright D (1995) Diabetes mellitus as a risk factor for pancreatic cancer. A meta-analysis. JAMA 273: 1605-1609

Ferlay J, Bray F, Pisani P, Parkin D (2001) GLOBOCAN 2000: Cancer Incidence, Mortality and Prevalence Worldwide, Version 1.0. IARC CancerBase no. 5. Lyon: IARC Press

Friedman GD, van den Eeden SK (1993) Risk factors for pancreatic cancer: an exploratory study. Int J Epidemiol 22: 30-37
Gapstur SM, Gann P (2001) Is pancreatic cancer a preventable disease? JAMA 286: $967-968$

Gapstur SM, Gann PH, Lowe W, Liu K, Colangelo L, Dyer A (2000) Abnormal glucose metabolism and pancreatic cancer mortality. JAMA 283: 2552-2558

Ghadirian P, Simard A, Baillargeon J, Maisonneuve P, Boyle P (1991) Nutritional factors and pancreatic cancer in the francophone community in Montreal, Canada. Int J Cancer 47: 1-6

Greenland S (1987) Quantitative methods in the review of epidemiologic literature. Epidemiol Rev 9: 1-30

Hanley AJ, Johnson KC, Villeneuve PJ, Mao Y, Canadian Cancer Registries Epidemiology Research Group (2001) Physical activity, anthropometric factors and risk of pancreatic cancer: results from the Canadian enhanced cancer surveillance system. Int J Cancer 94: 140 - 147

Howe GR, Jain M, Miller AB (1990) Dietary factors and risk of pancreatic cancer: results of a Canadian population-based case-control study. Int $J$ Cancer 45: 604-608 
IARC (2002) IARC Handbooks of Cancer Prevention, Vol 6. Weight Control and Physical Activity. Lyon: IARC Press

International Agency for Research on Cancer (1990) Cancer: Causes, Occurrence and Control. Lyon: IARC Press

Istvan JA, Cunningham TW, Garfinkel L (1992) Cigarette smoking and body weight in the Cancer Prevention Study I. Int J Epidemiol 21: 849-853

Ji BT, Hatch MC, Chow WH, McLaughlin JK, Dai Q, Howe GR, Gao YT, Fraumeni JF Jr (1996) Anthropometric and reproductive factors and the risk of pancreatic cancer: a case-control study in Shanghai, China. Int J Cancer 66: $432-437$

Lee IM, Sesso HD, Oguma Y, Paffenbarger RS Jr (2003) Physical activity, body weight, and pancreatic cancer mortality. Br I Cancer 88: 679-683

Lyon JL, Slattery ML, Mahoney AW, Robison LM (1993) Dietary intake as a risk factor for cancer of the exocrine pancreas. Cancer Epidemiol Biomarkers Prev 2: $513-518$

Michaud DS, Giovannucci E, Willett WC, Colditz GA, Stampfer MJ, Fuchs CS (2001) Physical activity, obesity, height, and the risk of pancreatic cancer. JAMA 286: 921 - 929

Moller H, Mellemgaard A, Lindvig K, Olsen JH (1994) Obesity and cancer risk: a Danish record-linkage study. Eur J Cancer 30A: 344-350

Shibata A, Mack TM, Paganini-Hill A, Ross RK, Henderson BE (1994) A prospective study of pancreatic cancer in the elderly. Int J Cancer 58: $46-49$

Silverman DT, Schiffman M, Everhart J, Goldstein A, Lillemoe KD, Swanson GM, Schwartz AG, Brown LM, Greenberg RS, Schoenberg JB, Pottern LM, Hoover RN, Fraumeni JF Jr 1999) Diabetes mellitus, other medical conditions and familial history of cancer as risk factors for pancreatic cancer. Br J Cancer 80: $1830-1837$

Silverman DT, Swanson CA, Gridley G, Wacholder S, Greenberg RS, Brown LM, Hayes RB, Swanson GM, Schoenberg JB, Pottern LM, Schwartz AG, Fraumeni JF Jr, Hoover RN (1998) Dietary and nutritional factors and pancreatic cancer: a case-control study based on direct interviews. $J$ Natl Cancer Inst 90: 1710-1719

Spencer EA, Appleby PN, Davey GK, Key TJ (2002) Validity of self-reported height and weight in 4808 EPIC-Oxford participants. Public Health Nutr 5: $561-565$

Stolzenberg-Solomon RZ, Pietinen P, Taylor PR, Virtamo J, Albanes D (2002) A prospective study of medical conditions, anthropometry, physical activity, and pancreatic cancer in male smokers (Finland). Cancer Causes Control 13: 417-426

Ursin G, Longnecker MP, Haile RW, Greenland S (1995) A meta-analysis of body mass index and risk of premenopausal breast cancer. Epidemiology 6: $137-141$

WHO, IASO and IOT (2000) The Asia-Pacific perspective: redefining obesity and its treatment. http://www.obesityasiapacific.com/ default.htm

Wolk A, Gridley G, Svensson M, Nyren O, McLaughlin JK, Fraumeni JF, Adami HO (2001) A prospective study of obesity and cancer risk (Sweden). Cancer Causes Control 12: 13-21

Zatonski W, Przewozniak K, Howe GR, Maisonneuve P, Walker AM, Boyle P (1991) Nutritional factors and pancreatic cancer: a case-control study from south-west Poland. Int J Cancer 48: 390-394 